\title{
Un verso de silencio. \\ Treinta y cinco poemas \\ de Adriane Garcia
}

\section{Selección y traducción de Manuel Barrós}

\footnotetext{
A

driane Garcia (Belo Horizonte, 1973) es historiadora, educadora y actriz. Escribe poesía, cuentos, libros infantiles y juveniles, además de teatro. Ganó el Prêmio Paraná de Literatura Helena Kolody en 2013 con el poemario Fábulas para adulto perder o sono (editado en 2017). Ha publicado o nome do mundo (2014), Só, com peixes (2015), Embrulhado para viagem (2016), Garrafas ao mar (2018) y Arraial do curral del Rei (2020).
} 
O senhor tem fogo?

Cada vez mais curtos

Os meus cabelos

Começo a ter visões de guerras

Às quais

Fui

Agora sou chamada a um

Milagre

Joana, a dark:

Essa fogueira

Que se apagava.

\section{Excesso de sol}

Tornei-me astigmática

Por prudência

Para que não amasse a Luz

Em excesso

Para que intuísse

Os benefícios

Das sombras

o puro paraíso

Cegava

Lúcifer odiava

o próprio nome

E pedia lentes

Transitions

Suas pupilas dilatadas

Anunciavam morte

Jamais um homem

Ou um anjo

Poderia olhar diretamente

Para Deus.

\section{¿Tiene usted un encendedor?}

Cada vez más cortos

Mis cabellos

Comienzo a tener visiones de guerras

A las cuales

Fui

Ahora soy llamada a un

Milagro

Juana, la dark:

Esa hoguera

Que se extinguía.

\section{Exceso de sol}

Me volví astigmática

Por prudencia

Para no amar la Luz

En exceso

Para intuir

Los beneficios

De las sombras

El puro paraíso

Cegaba

Lucifer odiaba

Su propio nombre

Y pedía lentes

Transitions

Sus pupilas dilatadas

Anunciaban muerte

Jamás un hombre

O un ángel

Podría mirar directamente

A Dios.

1 Todos los poemas de la presente selección provienen de la siguiente fuente: Garcia, Adriane (2018), Garrafas ao mar, São Paulo, Penalux. 


\section{Constrangimento}

Na sala de estar

Os presentes se

Entreolham

Com o mal estar

De nunca terem construído

Uma sala de ser.

\section{O Grito}

É um susto constante

Te roubam à escuridão do dia

Tu estás passando e

Levam teu ponteiro das horas

Enfiam tua voz no bolso

Quando percebem na correria

Que teu coração e tua identidade

Estavam no meio

Descartam-nos para trás

No chão sujo cuspido

Os carros passam por cima

$\mathrm{Tu}$ levantas os braços

Edvard Munch te pinta:

É um assalto.

\section{O coelho e a tartaruga}

o ódio corre

Muito

Rápido e cheio de

Equipamentos

O amor vai

Limpo

Devagar e

Sempre.

\section{Constreñimiento}

En el cuarto de estar

Los presentes se

Miraban unos a otros

Con el malestar

De nunca haber construido

Un cuarto de ser.

\section{E1 Grito}

Es un susto constante

Te roban en la oscuridad del día

Estás pasando y

Toman tu puntero de las horas

Ensartan tu voz al bolso

Cuando perciben en la carrera

Que tu corazón y tu identidad

Estaban en juego

Nos arrojan atrás

En el suelo sucio escupido

Los carros pasan por encima

Levantas los brazos

Edvard Munch te pinta:

Es un asalto.

\section{El conejo y la tortuga}

El odio corre

Muy

Rápido y lleno de

Cosas

El amor va

Limpio

Despacio y

Siempre. 


\section{Inadequação}

Saber que há flores

Estando onde só há

Deserto.

\section{Aos 40}

Não tenho saudade das que fui

As minhas mortas estão mortas

E enterradas

Levei flores de muito agradecimento

Mas deixei claro

Que não volto

Ao cemitério.

\section{Poesia geriátrica}

Ignora

A vida útil das palavras.

\section{De rerum natura}

(sobre a natureza das coisas)

Quando queimaram

Giordano Bruno

Eu o amava perdidamente

Fazíamos amor apenas

Com a respiração

Foi Bruno quem me ensinou

Sobre almas ligadas

Sobre labaredas e ventos

Havia um só espírito nas coisas todas

E era de saber de memória que

Meu Bruno as coordenava

Deus amava Bruno porque

Nada separava de si esse homem

Naquele fim dos meus XVI

A minha Terra

Girava

Em torno de Giordano.

\section{Inadecuación}

Saber que hay flores

Estando donde sólo hay

Desierto.

\section{A $\operatorname{los} 40$}

No tengo nostalgia de las que fui

Mis muertas están muertas

Y enterradas

Les llevé flores de mucha gratitud

Pero les dejé claro

Que no vuelvo

Al cementerio.

\section{Poesía geriátrica}

Ignora

La vida útil de las palabras.

\section{De rerum natura}

(de la naturaleza de las cosas)

Cuando quemaron a

Giordano Bruno

Yo lo amaba perdidamente

Hacíamos el amor sólo

Con la respiración

Fue Bruno quien me enseñó

Sobre almas conectadas

Sobre fuegos y vientos

Había un solo espíritu en todas las cosas

Y era el de saber de memoria que

Mi Bruno las coordinaba

Dios amaba a Bruno porque

Nada separaba de sí a ese hombre

En aquel final de mis XVI

Mi Tierra

Giraba

En torno a Giordano. 


\section{Guerras santas}

Ter que vestir armadura

É desconfortável e sangra

A lataria enferrujada

É sempre tétano

Com quarenta graus

De febre

Ninguém faz um poema

Mas queima

E queimar, às vezes

É preciso

Para não alimentar mais

Fogueiras.

Dos encantamentos

Por muito tempo treinei

Encantamentos

Confesso que

Num concurso

Ganhei primeiro lugar

Vi copa no lugar de seca

Pássaro no lugar de sombra

Água no lugar de madeira

Corroída, carcomida de ilusão

(pangarés à solta eu

transformava em alazão)

E era tanto pégasus que

Quando eu caía

O chão voava

Agora desencanto

Para aprender novas magias:

E pau é pau

Pedra é pedra.

\section{Guerras santas}

Tener que usar armadura

Es incómodo y hace sangrar

La armadura oxidada

Siempre causa tétano

Con cuarenta grados

De fiebre

Nadie hace un poema

Pero se quema

Y quemarse, a veces

Es necesario

Para no alimentar más

Hogueras.

\section{De los encantamientos}

Por mucho tiempo practiqué

Encantamientos

Confieso que

En un concurso

Gané el primer puesto

Vi follaje en lugar de hojas secas

Pájaro en lugar de sombra

Agua en lugar de madera

Corroída, carcomida de ilusión

(un viejo caballo suelto yo

lo transformaba en alazán)

Y era tan Pegaso que

Cuando yo caía

El suelo volaba

Ahora desencanto

Para aprender nuevos trucos:

Y palo es palo

Piedra es piedra. 


\section{Angústia}

A membrana que recobre

O coração

Comprime alguma válvula

Um pericárdio

Dois gládios

Um ringue

A gente vai se

Digladiar

Até a morte.

\section{O eterno retorno}

Diuturnamente

Uma guerra é deflagrada:

A mesma guerra

A guerra de novo

Que perdemos na

Semana passada.

\section{Escrever}

Dou água para os meus

Unicórnios

E à tarde vou à costureira

Deus é engraçadinho

Deu-nos por dentro

Um irmão Lumière

Não pesquei nuvens

Hoje

Vou beber na taverna

E com um pouco de sorte

Talvez

Me perder na floresta

Quero contar

Mil mentiras

Pra cada verdade

Insuficiente.

\section{Angustia}

La membrana que recubre

El corazón

Comprime alguna válvula

Un pericardio

Dos gladios

Un ring

Vamos a

Digladiarnos

Hasta la muerte.

\section{El eterno retorno}

Diuturnamente

Una guerra estalla:

La misma guerra

De nuevo la guerra

Que perdimos la

Semana pasada.

\section{Escribir}

Doy agua a mis

Unicornios

Y por la tarde voy a la costurera

Dios es graciosito

Nos dio por dentro

Un hermano Lumière

No pesqué nubes

Hoy

Beberé en la taberna

Y con un poco de suerte

Tal vez

Me pierda en la floresta

Quiero contar

Mil mentiras

Para cada verdad

Insuficiente. 


\section{Heráclito}

Brincaríamos com os

Douradinhos

Amor?

$\mathrm{Eu}$ te convidei para

Sequestrarmos

Os peixinhos do aquário

Sem matá-los

Vamos devolver

(sussurros: esta roupa

nem nos serve)

Entra, amor

Naquele impossível

Mesmo rio

Comigo?

\section{Heráclito}

¿jugaríamos con los

Pecesitos

Amor?

Yo te invité para

Que atrapemos

Los pecesitos del acuario

Sin matarlos

Devolvámoslos

(susurros: esta ropa

no nos sirve)

¿Entras, amor

En aquel imposible

Mismo río

Conmigo?

\section{Mandante}

o lobo

Não se disfarça de

Ovelha

O lobo

Se disfarça de

Pastor.

\section{Dirigente}

El lobo

No se disfraza de

Oveja

El lobo

Se disfraza de

Pastor.
Inútil unção dos enfermos

o poeta não vai para o Céu

Já cometeu todos os

Pecados capitais

E mais uns

Que ele inventou

\section{Inútil unción de los enfermos}

El poeta no va al Cielo

Ya cometió todos los

Pecados capitales

Y algunos más

Que él inventó 
Não espere a correção do poeta

O poeta é torto, empenado

E, de verdade

Nunca obedece a ninguém

Jogue água benta no poeta

E verá

Onde há fumaça

E fogo.
No esperes la corrección del poeta

El poeta está torcido, deformado

$\mathrm{Y}$, ciertamente

Nunca obedece a nadie

Échale agua bendita al poeta

Y verás

Dónde hay humo

Y fuego.

\section{A despeito de}

à Marielle Franco

\author{
Mesmo não havendo esperanças \\ Agiremos como se houvesse \\ Jamais a adesão total \\ Ao mal, ao funesto, ao terror \\ Liberdade continuará pronunciada \\ Sobre ou sob as mordaças \\ Daremos trabalho, sempre \\ Como hidras de duas cabeças
}

Decepem-nos duas, nasceremos quatro

Temos o treino, a expertise, a inteligência

Dos secularmente derrotados.

\section{A pesar de}

a Marielle Franco

Incluso no habiendo esperanzas

Actuaremos como si las hubiera

Jamás la adhesión total

$\mathrm{Al} \mathrm{mal,} \mathrm{a} \mathrm{lo} \mathrm{funesto,} \mathrm{al} \mathrm{terror}$

La libertad seguirá pronunciada

Sobre o bajo las mordazas

Seremos incómodas, siempre

Como hidras de dos cabezas

Córtennos las dos, naceremos cuatro

Tenemos el entrenamiento, el saber, la

[inteligencia

De los secularmente derrotados.

\section{Um dia de cada vez}

Somando tudo

Dá zero

Garçom

Me vê só a dose de hoje.

\section{Un día a la vez}

Sumando todo

Da cero

Mozo

Sólo dame la dosis de hoy. 


\section{Pacificada}

Que liberdade essa

De encarar a dor

De não querer mais

Curá-la

De chamá-la para uma

Conversa

Quase todos os dias

E dizer: - senta aí

Quase o amor obrigatório e doído

Por uma parenta velha

Doente, chata e longeva

Que a gente aceitou

E não pode mais

Pôr pra fora de casa.

\section{Sosegada}

Qué libertad esa

De encarar el dolor

De no querer

Curarlo más

De llamarlo para una

Conversación

Casi todos los días

Y decirle: siéntate ahí

Casi el amor obligatorio y dolido

Por una pariente vieja

Enferma, aburrida y longeva

Que nosotros aceptamos

Y ya no podemos

dejarla fuera de casa.

\section{Los vivos}

De la no agresión

De la envidia nula

Del cobro reducido a

Cero

De la aceptación sin nombre y del

Silencio

Del libre transitar sin

Que me juzguen:

Me gustan más los muertos.

\section{Thomas More}

Soñé que éramos

Los hombres-pájaro

Y que cantábamos

Todos juntos

Durante

La puesta del sol

Era una escena para

Estrechar las manos

Y de merecer

La próxima mañana.

A próxima manhã. 


\section{Esgoto}

Mar morto

Mãe morta.

\section{Pós-Apocalipse}

Tudo era loucura

E miragem

A poltrona de luxo

o homem que

Se sentou

A guerra pela espuma

Que degenera

Depois da tempestade

Um último dilúvio

Que nos arrastou à morte

Abrandou a Terra

Formou poças

Vieram os pombos

Beber a água

Nem sabem se

Alguma sombra

Nos resta.

\section{Há anos-luz}

Estou atrasada

Vendo

Estrelas mortas.

\section{Cloaca}

Mar muerto

Madre muerta.

\section{Post-Apocalipsis}

Todo era locura

Y espejismo

El sillón de lujo

El hombre que

Se sentó

La guerra por la espuma

Que se estropea

Después de la tempestad

Un último diluvio

Que nos arrastró a la muerte

Ablandó la Tierra

Formó charcos

Vinieron las palomas a

Beber el agua

No saben si

Alguna sombra

Nos resta.

\section{Hace años luz}

Estoy retrasada

Viendo

Estrellas muertas.

\section{Do injusto}

o filho pródigo aparece

o pai prepara uma festa

O filho de todo dia

Chora e come o que resta.

\section{De lo injusto}

El hijo pródigo aparece

El padre prepara una fiesta

El hijo de todos los días

Llora y come lo que resta. 
No meio da minha multidão

Ser

E não ser:

Eis a solidão.

\section{Debaixo do sol}

Há hora de plantar

E hora de colher

Hora de comer

E hora de beber

Hora de chorar

E hora de se alegrar

Salomão certamente

Não conheceu, do seu palácio

os homens-rato

Revirando o lixo nesta manhã.

\section{Aquiles}

Tenho um corte no

Calcanhar

Quase não se nota, parece

Cicatrizado

Em cima tatuei um ramo

De flores

Desavisados dizem que

É bonito

Acontece

Se mexo

Se mexem

Se piso em

Falso

Sinto

Um gosto de

Sangue.

\section{En medio de mi multitud}

Ser

Y no ser:

He ahí la soledad.

\section{Debajo del sol}

Hay tiempo de plantar

Y tiempo de cosechar

Tiempo de comer

Y tiempo de beber

Tiempo de llorar

Y tiempo de alegrarse

Ciertamente Salomón

No conoció, desde su palacio

A los recicladores

Que rebuscan en la basura esta mañana.

\section{Aquiles}

Tengo un corte en el

Talón

Casi no se nota, parece

Cicatrizado

Encima tatué un ramo

De flores

Los imprudentes dicen que

Se ve bonito

Sucede que

Si lo toco

Si lo tocan

Si piso en

Falso

Siento

Un sabor a

Sangre. 


\section{Mantra}

Quando não houver o que falar

Faça um verso de silêncio.

Ecce bomo

Jesus disse

Ama o próximo

Como a ti mesmo

Nietzsche repetía

Torna-te

Quem tu és

Só depois do segundo

Pude entender

o primeiro.

\section{Inventário}

A primeira coragem

É a de saber

Morrer

A segunda, a de matar

Só a sétima fênix

É a verdadeira.

\section{Mantra}

Cuando no haya qué decir

Haz un verso de silencio.

\section{Ecce homo}

Jesús dijo

Ama al prójimo

Como a ti mismo

Nietzsche repetía

Conviértete

En lo que eres.

Sólo después del segundo

Pude entender

Al primero.

\section{Inventario}

El primer coraje

Es el de saber

Morir

El segundo, el de matar

Sólo el séptimo fénix

Es el verdadero.

\section{A matéria prima}

Teias são tecidas

Da vida das aranhas

Não é o fio

Mas o caminho

Que enreda a trama.

\section{La materia prima}

Las telas son tejidas

De la vida de las arañas

No es el hilo

Sino el camino

Que enreda la trama. 


\section{Os inocentes pés das abelhas}

Flores são armadilhas

Só querem sexo

E filhos.

\section{Garrafas ao mar}

Pedi socorro por tantos dias quantos foram Os de minha vida

Também encontrei garrafas

Às quais não abri

No fim, soube que o mar morria

E que encontraram baleias mortas

Abarrotadas de mensagens no estômago

Talvez, algumas delas fossem minhas

Sim, eu tive baleias na infância.

\section{Los inocentes pies de las abejas}

Las flores son trampas

Sólo quieren sexo

E hijos.

\section{Botellas al mar}

Pedí auxilio por tantos días como fueron

Los de mi vida

También encontré botellas

Que no abrí

Al final, supe que el mar moría

Y que encontraron ballenas muertas

Abarrotadas de mensajes en el estómago

Tal vez, algunas de ellas fueron mías

Sí, yo tuve ballenas en la infancia.
Manuel Barrós. (Lima, 1993). Licenciado en Sociología por la Pontificia Universidad Católica del Perú (PUCP), Perú. Ha publicado la traducción Doze noturnos da Holanda / Doce nocturnos de Holanda (Ediciones Andesgraund, 2016; 2018), de Cecília Meireles, además de versiones de distintos escritores y poetas en diversas revistas.. Sus intereses de investigación son: sociología de la literatura, traducción literaria, poesía, historia del libro, herencia africana y literatura latinoamericana. 